\title{
MEASUREMENTS OF PULMONARY DIFFUSING CAPACITY IN CHILDREN
}

\author{
BY \\ L. B. STRANG* \\ From the Department of Child Health, University of Durham
}

(RECEIVED FOR PUBLICATION NOVEMBER 16, 1959)

Since the early studies of the Kroghs (Krogh, 1915) a number of investigators have employed low concentrations of carbon monoxide (CO) in order to study the diffusing capacity of the lungs. Carbon monoxide is taken up avidly by red blood cells in the pulmonary capillaries as it has $\mathbf{2 1 0}$ times the affinity for haemoglobin that oxygen has. For this reason, during the breathing of low concentrations of $\mathrm{CO}$ the tension of this gas in the blood plasma may be regarded as zero. If this assumption is made the diffusing capacity of the lungs for $\mathrm{CO}$ (Dco) can be derived from a knowledge of the mean alveolar $\mathrm{CO}$ concentration and the uptake of $\mathrm{CO}$ over a fixed time interval. Difficulties arise mainly in arriving at a valid figure for the mean alveolar $\mathrm{CO}$ tension and in controlling the variations in diffusing capacity which occur in differing states of rest or exercise. The diffusion velocities of carbon monoxide (CO) and oxygen $\left(\mathrm{O}_{2}\right)$ are proportional to the ratio of their solubilities and inversely proportional to the ratio of the square roots of their molecular weights. The diffusing capacities of the lung for $\mathrm{CO}$ and $\mathrm{O}_{2}$ (Dco and $\mathrm{Do}_{2}$ ) can be regarded as similarly related, the Dco being converted to $\mathrm{Do}_{2}$ by multiplying by a factor of $1 \cdot 23$ (Krogh, 1915).

A number of clinical methods have been devised for measuring the Dco using either steady state or single breath methods (Filley, MacKintosh and Wright, 1954; Forster, Fowler, Bates and Van Lingen, 1954; Bates, Boucot and Dormer, 1955; Gilson and Hugh-Jones, 1955; Ogilvie, Forster, Blakemore and Morton, 1957). The values obtained in normals and in patients with pulmonary diseases differ depending on the method used, the greatest difference being between single breath and steady state procedures. Because of these discrepancies and for other reasons the exact significance of these methods and the differences between them is rather uncertain. Nevertheless, there is no doubt

\footnotetext{
* Now at Postgraduate Medical School of London, Ducane Rd., London, W.12.
}

that abnormalities affecting gas uptake in the lungs can be detected by one or other of them, and in approaching the general problem of pulmonary function testing in children it seemed reasonable to use a $\mathrm{CO}$ method in order to estimate the possible extent of gas exchange abnormalities in children with pulmonary disease.

It was preferred to use a method involving a minimum of discomfort for the child and no arterial punctures and for these reasons a method of Bates (Bates et al., 1955) with some simplifications was employed.

In this method the $\mathrm{CO}$ tension of an end-tidal sample is taken as representing the mean alveolar tension of this gas.

\section{Methods}

Clinical Material. Four groups were examined: 79 normal children, 37 with bronchiectasis, 15 with asthma, and two with diffuse pulmonary disease.

The normal children were hospital in-patients and out-patients in whom cardiac and pulmonary disease had been excluded on clinical grounds. Thirty-five were girls, 44 were boys, and their ages were 5-14 years. Each child was tested on one occasion.

The 37 children with bronchiectasis were included in a previous study of ventilatory capacity abnormalities (Strang, 1960). All of them had cough, purulent sputum and abnormal segmental opacities on plain radiographs of the chest, and in 34 of them the presence of bronchiectasis had been confirmed on bronchography. Fifty-eight measurements of Dco were performed, 16 of the children being tested on two or more occasions. To allow comparison of functional and clinical data these patients were allocated to three grades of severity of symptoms and into three categories of increasing diffuseness of râles or rhonchi on auscultation of the chest. An exact definition of the groups is contained in a previous paper (Strang, 1960). The child was allocated to the categories without knowledge of the results for Dco. For comparison with radiological appearances a count was made of the numbers of bronchopulmonary segments seen to be involved on plain radiographs and bronchograms.

The 15 children with asthma were each tested on one 
occasion. Eosinophilia and impaired ventilatory capacity had been detected at some stage in each of them. None of them had permanent segmental shadows in plain radiographs of the chest but four of them habitually expectorated purulent sputum.

Of the two children with diffuse pulmonary disease one child had severe pulmonary infection associated with fibrocystic disease of the pancreas, and the other, idiopathic pulmonary haemosiderosis. The latter child had had repeated haemoptyses over a period of five years and radiological changes characteristic of the condition. Each of these children was tested on three separate occasions.

Apparatus and Procedure. The apparatus (Fig. 1) consisted of a 50 litre plastic bag A connected by a two-way tap and 0.75 in. diameter tubing to a 'Ruben' valve assembly B. This was fitted with a 'B.M.R.' mouthpiece and connected by tubing on the expiratory side to a 15 litre plastic bag $C$ fitted with a two-way tap. The 'Ruben' valve was modified to include an OtisRahn end-tidal sampler $D$ and this was connected by a sampling pump to a small 0.5 litre plastic bag $\mathbf{E}$ fitted with a two-way tap.

The bags were arranged on either side of a small table and the valve assembly and mouthpiece were attached to the table by an easily adjusted flexible clamp holder. During testing, the child sat comfortably at the table and, after a brief settling-down period, was connected to A which contained a prepared mixture of $0 \cdot 1 \% \mathrm{CO}$ in air. At the same time the Otis-Rahn sampler was connected to the pump operating at $250 \mathrm{ml}$. per min. After 1.5-2 min. to allow for clearing of the dead space of the apparatus and equilibration in the lungs, the expired gas was collected in $\mathrm{C}$ for $1 \mathrm{~min}$. by a stopwatch. The end-tidal sample was collected over $1.5 \mathrm{~min}$. which ensured an adequate size of sample. At the end of the procedure, the concentrations of $\mathrm{CO}$ in the inspired, expired and end-tidal samples were measured by passing through an infra-red



Fig. 1.-Apparatus for measurement of Dco-see text. gas analyser,* and the volume of gas in bag $\mathbf{C}$ was measured by passing it through a gas meter. $\dagger$ The minute ventilation was taken as this volume plus the volume removed for sampling and the volume of the end-tidal sample.

From these readings the Dco (in $\mathrm{ml} . / \mathrm{min} . / \mathrm{mm}$. $\mathrm{Hg}$ partial pressure difference of $\mathrm{CO}$ ) was calculated according to the following expression, the tension of $\mathrm{CO}$ in the pulmonary capillary blood being taken as zero:

$$
\text { Dco }=\frac{\dot{\mathrm{V}}(\mathrm{FI}-\mathrm{FE})}{\text { FET. }(\mathrm{B}-47)}
$$

(where $\dot{\mathbf{V}}$ is minute ventilation, FI, FE and FET, are fractions of $\mathrm{CO}$ in inspired, expired and end-tidal gas, and $\mathbf{B}$ is barometric pressure).

Each child was tested twice and the result expressed as a mean of the two readings. The amount of blood inactivated by conversion of haemoglobin to carboxyhaemoglobin was estimated to be in the order of $30-50 \mathrm{ml}$. for the whole procedure.

\section{Results}

Normals. The coefficient of variation of a single estimate of Dco was $10 \cdot 2 \%$. A significant positive correlation was found between Dco and the child's height, weight, surface area and age (Table 1). The correlation with surface area was better than with the other parameters tested but that with height was almost as good and the results are presented as a regression on the height with intervals of two standard deviations (Fig. 2).

TABLE 1

CORRELATIONS OF DCO WITH AGE AND VARIOUS BODY MEASUREMENTS (79 NORMAL CHILDREN)

\begin{tabular}{|c|c|c|c|c|c|}
\hline & & & & & Correlation Coefficient ( $r$ ) \\
\hline $\begin{array}{l}\text { Surface area } \\
\text { Height } \\
\text { Weight } \\
\text { Age ... }\end{array}$ & $\begin{array}{l}\cdots \\
\cdots \\
\cdots\end{array}$ & $\begin{array}{l}\cdots \\
\cdots \\
\cdots\end{array}$ & $\begin{array}{l}\cdots \\
\cdots \\
\cdots\end{array}$ & $\begin{array}{l}\cdots \\
\cdots \\
\cdots\end{array}$ & $\begin{array}{l}0.654 \\
0.635 \\
0.620 \\
0.511\end{array}$ \\
\hline
\end{tabular}

Bronchiectasis. The results in 34 children with bronchiectasis are shown in Fig. 3 and compared with the normal limits for height. Relatively few of these results were outside the normal limits but there was a trend towards lower values. This was shown in a significant difference between the mean of this group and the normals when both sets of data were expressed as a percentage of the normal mean for height. (Normal mean-100\%, S.E. $=2 \cdot 17$, $\mathrm{n}=79$; Bronchiectasis mean $=79 \%$, S.E. $2 \cdot 87$, $\mathrm{n}=58$.)

* Supplied by Sir Howard Grubb (Parsons) Limited.

$\dagger$ Supplied by Parkinson and Cowan Limited (Type C.D.4). 


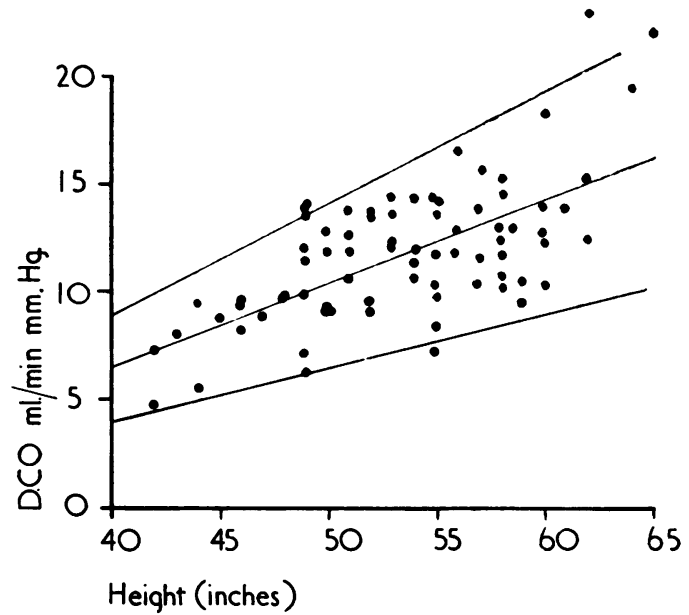

FIG. 2.-Dco of 79 normal children by height. 35 girls, 44 boys. Regression: Dco ml./min./mm. $\mathbf{H g}=0.390 \times$ Ht. (in.) $-9 \cdot 1$. (Coefficient of variation between children $=19 \cdot 3 \%$. $95 \%$ limits shown.

There appeared to be no significant relationship between Dco and the grades of severity or diffuseness of the bronchiectasis (Tables 2 and 3 ) and no obvious correlation with the numbers of abnormal segments counted on chest radiographs.

Asthma. The results are shown in Fig. 4 and compared with the normal limits for height. These patients were in differing states of ventilatory impairment, six of them having diffuse rhonchi on auscultation at the time of testing. The results,



Fig. 4.-Dco of 15 children with asthma. Crosses represent children with no overt pulmonary infection. Circles represent children with purulent sputum.

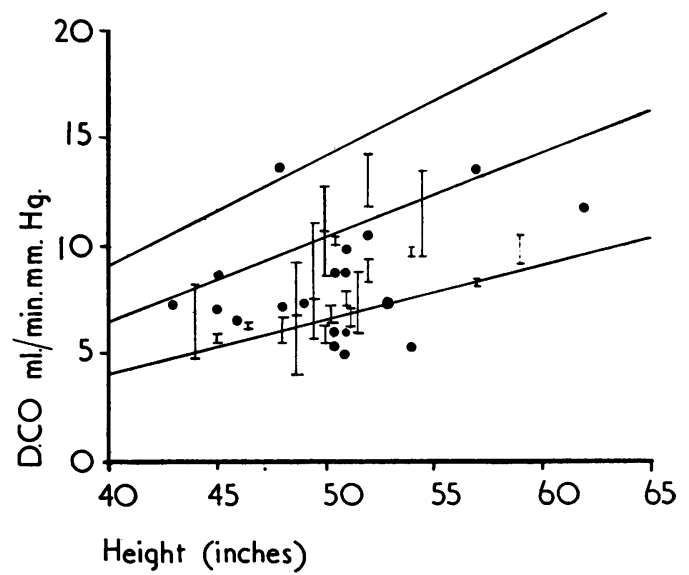

FIG. 3.-Dco of 37 children with bronchiectasis compared with normal limits for height. 58 observations. Repeated observations on one child are joined by a vertical line.

however, showed no important difference from the normal and they were not analysed further.

Diffuse Pulmonary Lesions. The results on these two patients, each tested on three separate occasions, are shown in Fig. 5 and compared with the normal limits for height. The child with fibrocystic disease was within normal. The child with idiopathic pulmonary haemosiderosis had a severe impairment of diffusing capacity and this finding was highly repeatable.

- idiopathic pulmonary haemosiderosis

a fibrocystic disease of poncreas

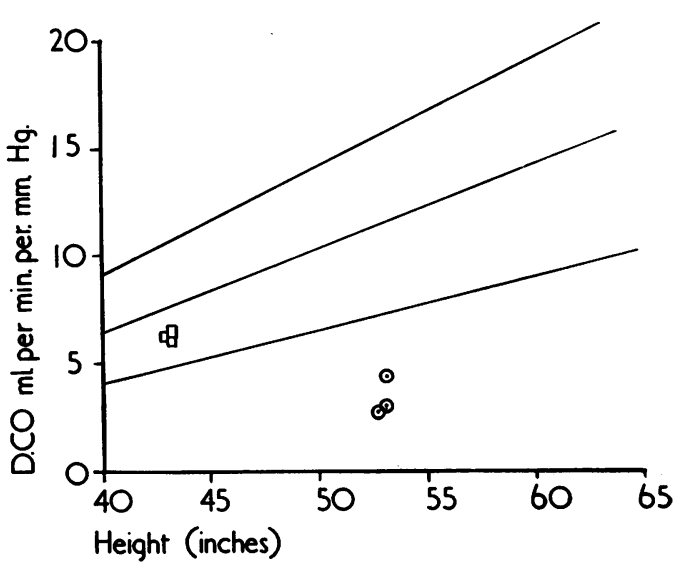

FIG. 5.-Dco in two children with diffuse pulmonary disease. 
TABLE 2

Dco AND CLINICAL ESTIMATE OF SEVERITY OF BRONCHIECTASIS (59 OBSERVATIONS, 34 CHILDREN)

\begin{tabular}{|c|c|c|c|c|}
\hline Grade of Severity & $\begin{array}{c}\text { No. of } \\
\text { Observations }\end{array}$ & $\begin{array}{l}\text { Mean Dco } \\
(\% \text { normal) }\end{array}$ & $t$ & $\mathbf{p}$ \\
\hline 1 & 18 & $81 \cdot 6$ & \multirow{3}{*}{$\begin{array}{l}0.337 \\
1.065\end{array}$} & \multirow{3}{*}{$\begin{array}{l}>0.05 \\
>0.05\end{array}$} \\
\hline 2 & 31 & $79 \cdot 4$ & & \\
\hline 3 & 10 & $72 \cdot 0$ & & \\
\hline
\end{tabular}

\section{Discussion}

The Method. The method used to measure Dco can be criticized on at least two grounds. First, it could not be ensured that the children were completely at rest or in comparable states of activity during the procedure and some of them tended to hyperventilate. Second, it is quite possible that the end-tidal sample did not represent a true mean of the alveolar gas, the poorly ventilated areas of lung probably being under-represented. Alternative means of arriving at this value include calculation from the arterial $\mathrm{CO}_{2}$ tension (Filley et al., 1954), calculation from the Bohr equation using an assumed value for the anatomical dead-space (Bates et al., 1955) or the use of a single breath method after preliminary estimation of the functional residual capacity (Ogilvie et al., 1957). The first of these was not used because arterial punctures were considered undesirable in these patients; the second could not be used because reliable data for anatomical dead-space are lacking in children. The third possibility was rejected because it was thought that the timing of breath holding would require too great a degree of cooperation.

Normal Values. The results in normal children are presented as a regression on the standing height because this appears to be a better basis for comparison between normals and children with pulmonary disease than the weight or surface area which is derived from the height and weight. This is because children with pulmonary disease are frequently below normal in weight but seldom in height (Strang, 1960). The height was used as a basis for comparison in previous studies of ventilatory capacity and this is an additional reason for using it here, particularly as the correlation is only slightly less good than that with surface area.

Results in Pulmonary Diseases. Significant abnormalities of diffusing capacity would appear to be rare in children. The only undoubted example detected in this study was in the child with idiopathic pulmonary haemosiderosis. This finding was highly repeatable and it is probable that other similar
TABLE 3

Dco AND DIFFUSENESS OF SIGNS ON AUSCULTATION (59 OBSERVATIONS, 34 CHILDREN)

\begin{tabular}{|c|c|c|c|c|}
\hline Grade of Diffuseness & $\begin{array}{c}\text { No. of } \\
\text { Observations }\end{array}$ & $\begin{array}{l}\text { Mean Dco } \\
\text { (\% normal) }\end{array}$ & $t$ & p \\
\hline 1 & 19 & $84 \cdot 2$ & \multirow{3}{*}{$1 \cdot 49$} & \multirow{3}{*}{$>0.05$} \\
\hline 2 & 19 & $75 \cdot 1$ & & \\
\hline 3 & 21 & $76 \cdot 4$ & & \\
\hline
\end{tabular}

defects could be detected by this method. Diffuse infiltrative lesions of the lungs such as this are rare in childhood and the measurement of diffusing capacity is likely, therefore, to have a very limited application. It is certainly unlikely to be useful in studies of asthma and bronchiectasis.

The overall Dco measured by any steady-state technique such as the present one is dependent on the balance between ventilation and blood flow, and when inequalities of ventilation-bloodflow ratios exist, they will lead to lower values for the overall diffusing capacity, without there necessarily being any obstacle to diffusion in any individual part of the lung (Forster et al., 1954). Bronchiectasis in children is a diffuse patchy condition (Whitwell, 1952) which might be expected to be associated with inequalities of ventilation and bloodflow, and it may be that the lower than normal values of Dco obtained in these children are due to this rather than to an impairment of diffusing capacity as usually understood. If this is so, an investigation of ventilation-bloodflow inequalities in this group might be rewarding.

\section{Summary}

Measurements of the diffusing capacity for carbon monoxide (Dco) in children are presented. The method appears to have a limited application in the study of pulmonary diseases in children.

\section{REFERENCES}

Bates, D. V., Boucot, N. G. and Dormer, A. E. (1955). The pulmonary diffusing capacity in normal subjects. J. Physiol. (Lond.), 129,237

Filley, G. F., MacKintosh, D. J. and Wright, G. W. (1954). Carbon monoxide uptake and pulmonary diffusing capacity in normal subjects at rest and during exercise. J. clin. Invest., 33, 530.

Forster, R. E., Fowler, W. S., Bates, D. V. and Van Lingen, B. (1954). The absorption of carbon monoxide by the lungs during breathholding. J. clin. Invest., 33, 1135.

Gilson, J. C. and Hugh-Jones, P. (1955). Lung function in coalworkers' pneumoconiosis. Spec. Rep. Ser. med. Res. Coun. (Lond.), No. 290

Krogh, M. (1915). The diffusion of gases through the lungs of man. J. Physiol. (Lond.), 49, 271.

Ogilvie, C. M., Forster, R. E., Blakemore, W. S. and Morton, J. W. (1957). A standardized breath holding technique for the clinical measurement of the diffusing capacity of the lung for carbon monoxide. J. clin. Invest., 36, 1 .

Strang, L. B. (1960). Abnormalities of ventilatory capacity in children with asthma and bronchiectasis. Arch. Dis. Childh., 35, 224.

Whitwell, F. (1952). A study of the pathology and pathogenesis of bronchiectasis. Thorax, 7,213 . 